\title{
Reliability of prestressed concrete structures considering creep models
}

\author{
Alaa M. Chateauneuf ${ }^{\mathrm{a}}$, Wassim E. Raphael ${ }^{\mathrm{b}}$ and Rostand J.B. Moutou Pitti $^{\mathrm{a}}$ \\ ${ }^{a}$ Institut Pascal, University Blaise Pascal, Clermont University, CNRS, UMR 6602, BP 10448, 63000 Clermont-Ferrand, France; \\ ${ }^{b}$ University Saint Joseph, ESIB, Mkalles, Mar Roukos, BP 11-514, Riad El Solh, Beirut, Lebanon
}

\begin{abstract}
The reliability of prestressed concrete structures subject to viscoelastic behaviour is investigated regarding the creep model defined by the Eurocodes. A probabilistic phenomenological model is proposed for long-term creep strains on the basis of large database of creep tests. The uncertainties in the geometrical and mechanical parameters are modelled by random variables. The proposed model considers also the statistical fitting error in creep strain predictions. The reliability analysis is performed on a prestressed concrete deck, in order to show the large impact of time-dependent phenomena on the reliability of prestressed structures, and consequently the importance of considering appropriate viscoelastic models in the design of this kind of structures. Moreover, the errors related to creep models are shown to play a very important role in the structural safety assessment.
\end{abstract}

Keywords: prestressed concrete structures; bridges; reliability; durability; creep models

\section{List of symbols}

\begin{tabular}{|c|c|}
\hline$A_{\mathrm{c}}:$ & concrete cross section \\
\hline$E_{\mathrm{cm}}\left(t_{0}\right)$ & $\begin{array}{l}\text { mean secant modulus of concrete at } \\
\text { time } t_{0}\end{array}$ \\
\hline$E_{\mathrm{cm}}:$ & $\begin{array}{l}\text { mean secant modulus of concrete at } \\
28 \text { days }\end{array}$ \\
\hline$E_{\mathrm{i}}\left(t_{0}\right):$ & instantaneous modulus at the age $t_{0}$ \\
\hline$f_{\mathrm{cm}}:$ & $\begin{array}{l}\text { mean compressive concrete strength at } \\
28 \text { days }\end{array}$ \\
\hline$f_{c k}:$ & $\begin{array}{l}\text { characteristic value of compressive } \\
\text { concrete strength }\end{array}$ \\
\hline$\beta_{\mathrm{H}}, \varphi_{\mathrm{RH}}:$ & $\begin{array}{l}\text { coefficients depending on relative } \\
\text { humidity }\end{array}$ \\
\hline$h_{0}:$ & notional member size \\
\hline$u:$ & $\begin{array}{l}\text { cross-section perimeter subject to the } \\
\text { environment effects }\end{array}$ \\
\hline$J_{i j k l}:$ & creep compliance tensor \\
\hline$J\left(t, t_{0}\right):$ & $\begin{array}{l}\text { creep function at time } t \text { when prestres- } \\
\text { sing is applied at } t_{0}\end{array}$ \\
\hline$\varphi\left(t, t_{0}\right):$ & $\begin{array}{l}\text { creep coefficient at time } t \text { when } \\
\text { prestressing is applied }\end{array}$ \\
\hline$\delta:$ & model error due to data scatter \\
\hline$\varepsilon_{\mathrm{ftot}}(t), \varepsilon_{0}\left(t_{0}\right), \varepsilon_{\mathrm{c}}(t)$ & $\begin{array}{l}\text { total, instantaneous and creep strains, } \\
\text { respectively }\end{array}$ \\
\hline$\sigma_{i j}, \quad \varepsilon_{i j}$ & stress and strain tensor component \\
\hline$\Delta P c:$ & restress losses induced by creep \\
\hline
\end{tabular}

\section{Introduction}

Creep plays an important role, sometimes crucial, in the in-service behaviour of concrete structures, especially for long-term integrity of prestressed concrete. Inaccurate prediction of creep deformations leads to undesirable consequences for designers, constructors, owners, users, insurers, etc. Under the effect of long-term loading, environment and prestressing, concrete material undergoes large viscoelastic strains (Miyagawa, 2006; Mohsen \& Ahmad, 1995; Moutou Pitti, Dubois, \& Petit, 2010; Raphael, Faddoul, El-Asmar Selouan, \& Chateuneuf, 2009) which decrease their performance and may lead to structural collapse. Recent developments of viscoelastic models (Chazal and Moutou Pitti, 2010; Seongcheol, Soo Won Cha, \& Hwan, 2010) provide a better understanding of this phenomenon and consequently improve the lifetime prediction. Nevertheless, this forecast is subjected to uncertainties which are mainly due to the calibration of viscoelastic parameters, the variability of the loads during the structural lifetime and, finally, the short- and long-term evolution of concrete properties.

In civil engineering literature, many authors have considered the time-dependent phenomena in concrete structures. Among them, Destrebecq and Jurkiewiez (2001) have proposed a numerical analysis of creep and relaxation in concrete bridges, by combining the incremental formulation in Ghazlan, Caperaa, and Petit (1995) and the creep law in Bazant and Carol (1974). In fracture mechanics, the incremental viscoelastic formulation (Moutou Pitti, Dubois, Pop, \& Absi, 2009) has been applied in order to model the crack propagation in structures. Judycki (1992) has discussed the nonlinear viscoelastic behaviour in asphaltic concrete structures. In order to take into account the random behaviour of 
viscoelastic parameters in structural durability, Gabrielsen (1968) has proposed stochastic models for viscoelastic materials, and Jordan (1980) has applied the probabilistic analysis to concrete under creep loading.

The creep phenomenon has a double effect on prestressed concrete structures as it induces long-term concrete deformations, on one hand, and prestressing force losses, on the other hand. The prestressing losses may increase concrete cracking and therefore affects the serviceability limit state. In this work, the reliability analysis of prestressed concrete structures under creep is considered. The creep formulation defined by the Eurocodes (CEN, 2004) is compared with a large database of creep tests. In order to better fit the test results, a probabilistic phenomenological model is proposed, where the model uncertainty is evaluated in terms of data scatter. In addition, the uncertainties in geometrical and mechanical parameters of the structure are modelled by random variables and the first-order reliability method FORM (Lemaire, Chateauneuf, \& Mitteau, 2010; Soares, Chateauneuf, Venturini, \& Lemaire, 2002) is applied to evaluate the failure probability.

In the following sections, the creep model adopted in the Eurocodes is described and then compared with test results. The probabilistic phenomenological model is then defined in order to better fit the creep data. Finally, the proposed model is applied to a bridge deck in order to show the high importance of viscoelastic parameters and model errors in the assessment of structural reliability.

\section{Creep models for concrete}

\subsection{Creep behaviour}

The concrete material is characterised by viscoelastic behaviour where strain comes from the combination of instantaneous and time-dependent parts. From the mechanical point of view, the behaviour of viscoelastic materials varies between the vitreous solid behaviour and the viscous behaviour according to loading conditions and climatic variations. Although the consideration of creep strain effects in viscoelastic materials is a current practice in engineering design, the creep models are still very poor

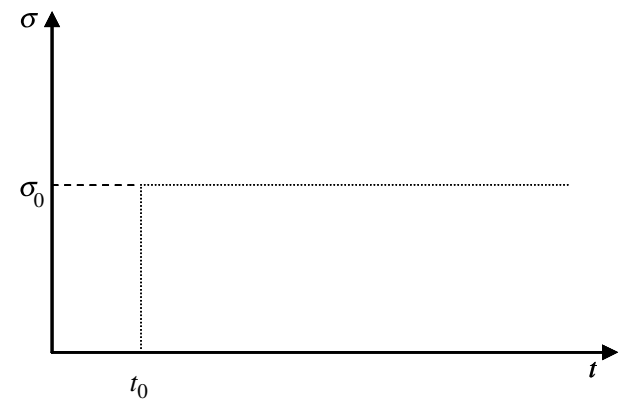

Figure 1. Applied stress profile and creep strain. in predicting appropriately the time-dependent deformations. Besides the model accuracy, the mechanical modelling of viscoelastic structures is facing difficulties related to large demand in computer resources, due to the need to integrate the whole history of the structure. Two alternatives can be proposed by using either empirical models (e.g. CEN, 2004) or incremental formulation (e.g. Chazal \& Moutou Pitti, 2010). The former has the advantage of simple use in engineering design, while the latter has the advantage of providing accurate results as long as the input parameters are well calibrated. In the present work, we consider only the empirical models which are mainly applied in civil engineering design procedures.

In general, the mechanical behaviour relating strain to stress history is given by the following expression (Moutou Pitti et al., 2009):

$$
\varepsilon_{i j}(t)=\int_{t_{0}}^{t} J_{i j k l}(t-\xi) \cdot \frac{\partial \sigma_{k l}}{\partial \tau} \mathrm{d} \xi
$$

where $\varepsilon_{i j}$ is the strain tensor, $\sigma_{k l}$ the corresponding stress tensor, $J_{i j k l}$ the fourth-order creep tensor, $t$ the actual time and $t_{0}$ the time at loading. In prestressed concrete, the viscoelastic behaviour mainly results from permanent loading, i.e. dead loads and prestress forces. The creep test consists in applying a constant stress which is maintained along the test duration (Figure 1). The elastic strain, observed instantaneously at the loading time $t_{0}$, is followed by a time-dependent strain known as creep strain. In this specific case, for a loading time $t_{0}$, the stress of amplitude $\sigma_{0}$ is applied according to the expression:

$$
\sigma(t)=\sigma_{0} \cdot H\left(t-t_{0}\right),
$$

where $H$ traduces the Heaviside function. The strain evolution as a function of time is given by

$$
\varepsilon(t)=\sigma_{0} \cdot J\left(t, t_{0}\right),
$$

where $J$ is the creep function for the time $t>t_{0}$. The solution of viscoelastic problems can be performed by

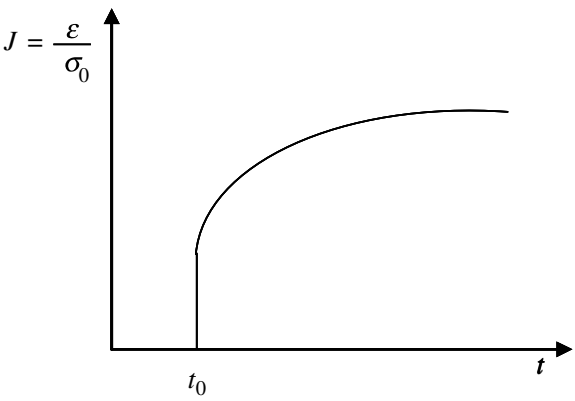


transforming the time-dependent problem into an equivalent elastic problem.

Instead of performing complex nonlinear analysis, the Eurocode 2 (CEN, 2004) proposes a simplified empirical formulation of the creep behaviour on the basis of strain decomposition in two parts: instantaneous and timedependent.

$$
\varepsilon(t)=\varepsilon_{0}\left(t_{0}\right)+\varepsilon_{\mathrm{c}}(t),
$$

where $\varepsilon(t)$ is the total strain, $\varepsilon_{0}\left(t_{0}\right)$ the instantaneous strain and $\varepsilon_{\mathrm{c}}(t)$ the creep strain. The formulation is summarised in the following section.

\subsection{Eurocode creep model}

The strain expression (4) can be rewritten in the form:

$$
\varepsilon(t)=\varepsilon_{0}\left(t_{0}\right) \cdot\left[1+\frac{\varepsilon_{\mathrm{c}}(t)}{\varepsilon_{0}\left(t_{0}\right)}\right]=\frac{\sigma_{0}}{E_{\mathrm{i}}\left(t_{0}\right)} \cdot\left[1+\varphi\left(t, t_{0}\right)\right]
$$

where $E_{\mathrm{i}}\left(t_{0}\right)$ is the instantaneous elastic modulus at the age $t_{0}$, and $\varphi\left(t, t_{0}\right)$ is the creep coefficient; thus,

$$
J\left(t, t_{0}\right)=\frac{\varepsilon(t)}{\sigma_{0}}=\frac{1}{E_{\mathrm{i}}\left(t_{0}\right)} \cdot\left[1+\varphi\left(t, t_{0}\right)\right] .
$$

The creep coefficient $\varphi\left(t, t_{0}\right)$ in this equation depends on the loading magnitude, time and duration. It represents the relationship between the free creep strain and the instantaneous strain. The creep function $J\left(t, t_{0}\right)$, also called compliance, depends on the creep coefficient and represents the total creep acting on the member under unit stress. The Eurocode 2 rewrites Equation (6) in terms of the mean secant modulus of concrete as follows:

$$
J\left(t, t_{0}\right)=\frac{1}{E_{\mathrm{cm}}\left(t_{0}\right)}+\frac{\varphi\left(t, t_{0}\right)}{E_{\mathrm{cm}}}
$$

where $E_{\mathrm{cm}}\left(t_{0}\right)$ is the mean secant modulus at loading time $t_{0}$ and $E_{\mathrm{cm}}$ the mean secant modulus at 28 days.

The creep coefficient $\varphi\left(t, t_{0}\right)$ is given by

$$
\varphi\left(t, t_{0}\right)=\varphi_{0} \times \beta_{\mathrm{c}}\left(t-t_{0}\right)
$$

with

$$
\begin{gathered}
\varphi_{0}=\varphi_{\mathrm{RH}} \times \beta\left(f_{\mathrm{cm}}\right) \times \beta\left(t_{0}\right) \quad \text { and } \\
\beta_{\mathrm{c}}\left(t-t_{0}\right)=\left[\frac{\left(t-t_{0}\right)}{\beta_{\mathrm{H}}+t-t_{0}}\right]^{0.3}, \\
\beta\left(f_{\mathrm{cm}}\right)=\frac{16.8}{\sqrt{f_{\mathrm{cm}}}} \text { and } \beta\left(t_{0}\right)=\frac{1}{0.1+t_{0}^{0.2}},
\end{gathered}
$$

where $f_{\mathrm{cm}}$ is the mean compressive strength of concrete at 28 days, $\beta_{\mathrm{H}}$ and $\varphi_{\mathrm{RH}}$ are coefficients depending on the relative humidity (RH \%) and the notional member size $h_{0}$. In the case of high strength concrete $f_{\mathrm{cm}}>35 \mathrm{MPa}$, these coefficients are given by

$$
\begin{aligned}
\beta_{\mathrm{H}} & =\max \left\{1.5\left[1+(0.012 \mathrm{RH})^{18}\right] h_{0}+250 \alpha_{3} 1500 \alpha_{3}\right\} \\
\varphi_{\mathrm{RH}} & =\left(1+\frac{1-R H / 100}{0.1 \sqrt[3]{h_{0}}} \alpha_{1}\right) \alpha_{2}
\end{aligned}
$$

with $\quad \alpha_{1}=\left(35 / f_{\mathrm{cm}}\right)^{0.7}, \quad \alpha_{1}=\left(35 / f_{\mathrm{cm}}\right)^{0.2} \quad$ and $\quad \alpha_{1}=$ $\left(35 / f_{\mathrm{cm}}\right)^{0.5}$. The notional member size $h_{0}(\mathrm{~mm})$ is given by

$$
h_{0}=\frac{2 \times A_{\mathrm{c}}}{u}
$$

where $A_{\mathrm{c}}$ is the concrete area and $u$ the cross-section perimeter exposed to environmental effects.

\subsection{Proposed creep model}

Creep deformations are very sensitive to material, structural and environmental conditions, leading to large scatter in the parameter estimation whatever the involved model. Moreover, uncertainties and fluctuations of the inservice conditions have great influence on the creep predictions. In this sense, the need for accurate model is mandatory for lifetime management of concrete structures. However, as it has been observed through field measurements on real structures (Delhomme, Baroudi, \& Debicki, 2009; Goel, Kumar, \& Paul, 2007; Takács, 2002), the design codes of practice are still unable to provide satisfactory physical explanations and predictions of creep deformation.

Takács (2002) compared the predictive models (namely CEB-FIP MC90 and B3 models) with real measurements in three bridges in Norway (Norddalsfjord, Støvset and Stolma Bridges) and found significant differences in most cases, without clear identification of the trend. Bažant and Guang-Hua (2008) and Bažant, Yu, and $\mathrm{Li}$ (2012) indicated that standard creep models give 18-year deflection estimates that are 50-77\% lower than measured and yield unrealistic shapes of deflection. For these reasons, the model uncertainties become, at least, as large as inherent statistical uncertainties.

In practice, three major sources of uncertainty can be observed in creep modelling (Raphael, 2002):

- Model errors: they result from ignorance or simplifications. In most of the cases, the underlying physical phenomena controlling the behaviour of the system are insufficiently understood and parameter interactions are hardly detected. Moreover, the model format may take inappropriate forms regarding the long-term material behaviour and operating conditions. 
- Measurement errors: a mathematical model is calibrated by using the available experimental data. However, the data are acquired by measurements which are prone to random and systematic errors. The use of inaccurate measurements to determine the model parameters leads to additional uncertainties in the predictive model.

- Statistical errors: in dealing with statistical models, an infinite set of data is required for each configuration, in order to find the 'exact' point estimates of the parameters. Due to high cost and destructive nature of testing, only limited data-sets are available in practice, leading to significant statistical uncertainties on parameter expectation and dispersion.

To cope with design code inadequacy, Raphael, Kaddah, Geara, Favre, and Calgaro (2002) have collected a large database for creep testing carried out by several research institutes in Europe. The database includes 432 creep tests on samples of various shapes and dimensions, under different environmental conditions. The specimens in the database were subjected to axial strain conditions, under the following testing configuration range:

- The tests are performed for different types of cement (classes S, N and R, i.e. slow, normal and rapid hardening), with nearly one-third of the number of tests undertaken with each cement type.

- The compressive strength of concrete at 28 days (MPa) varies between 11 and $118 \mathrm{MPa}$ while the mean radius $r_{\mathrm{m}}$ of the specimen varies from 1.75 to $15.25 \mathrm{~cm}$.

- Regarding the loading date $t_{0}$, it varies from 0.5 to 3300 days.

- The relative ambient humidity RH varies between $1 \%$ and $100 \%$.

- The applied stress $\sigma$ varies between 0.69 and 45.2 MPa.

The duration of the test after the loading date $\left(t-t_{0}\right)$ exceeds 3000 days for some experiments. The level of stress $\sigma / f_{\text {ckj }}$ does not exceed in any case the value of 0.4 (i. e. it varies for all tests between 0.06 and 0.383 ). Regarding the definition of creep strain levels, three categories of compliances are identified in the database:

- Small creep strain: 126 tests corresponding to creep compliance $J$ between 0 and $60 \times 10^{-6} \mathrm{MPa}^{-1}$.

- Moderate creep strain: 187 tests corresponding to creep compliance $J$ between $60 \times 10^{-6}$ and 120 $\times 10^{-6} \mathrm{MPa}^{-1}$.

- Large creep strain: 119 tests corresponding to creep compliance $J>120 \times 10^{-6} \mathrm{MPa}^{-1}$.

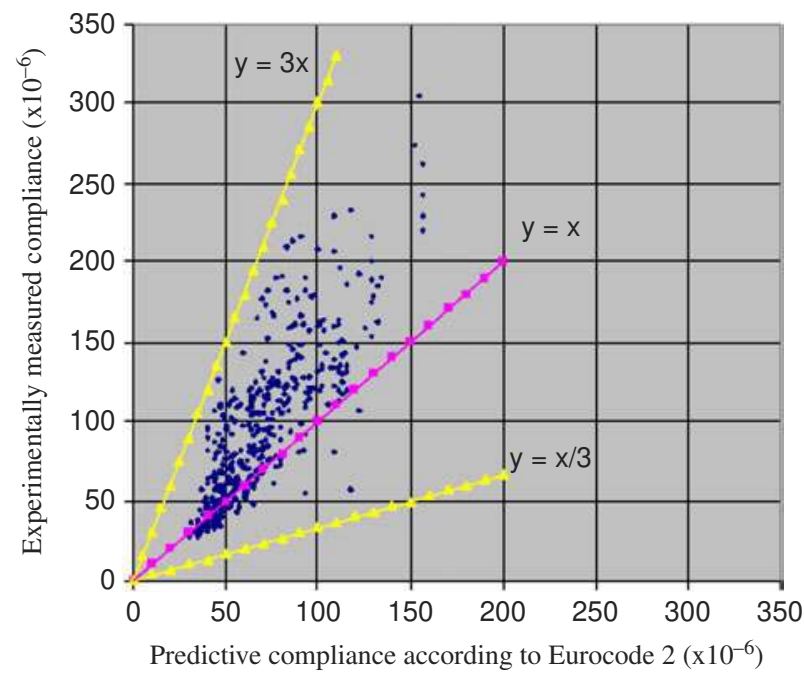

Figure 2. Eurcode 2 prediction versus experimental compliance $\left(\mathrm{MPa}^{-1}\right)$.

We want to mention that all the samples are doubled in the database. One of each sample is loaded (submitted to a stress level) while the second is not and is used to predict the shrinkage strain which is deducted from the total strain of the first sample. So the difference allows to eliminate the shrinkage, and therefore to get only creep strains.

This database allows us to verify the accuracy of the creep models defined in the codes of practice. Figure 2 plots the measured compliance (i.e. creep strain per unit stress) versus the Eurocode-predicted compliance, for all strain levels. In this figure, short- and long-term predictions are mixed. It is easy to see that accurate prediction of creep is only possible for small strains. On the opposite, the comparison of the experimental results with Eurocode predictions shows that the long-term creep strain is highly underestimated. In some cases, the error reaches up to $300 \%$. It can be clearly shown that the creep model underestimates, in most cases, the longterm strain.

In order to improve the long-term predictions, Raphael (2002) proposed a creep model on the basis of the analysis of creep behaviour; the model parameters are then fitted using the experimental database. The proposed model, known as MPF, is described as follows:

$$
J-J_{\text {init }}=A\left(1-\mathrm{e}^{-\left(\left(t-t_{0}\right) / 30\right)}\right)+B \log _{10}\left(\frac{t}{t_{0}}\right)
$$

where $t_{0}$ is the age of concrete at prestress application (days), $t$ the age of concrete at the considered time, $J$ the creep compliance and $J_{\text {init }}$ the compliance at $t=t_{0}$. The model constants $A, B$ and $J_{\text {init }}$ are evaluated by fitting 
the database results, leading to the following equations:

$$
\begin{aligned}
& J_{\text {init }}=32.963+0.225 A-0.0625 f_{\mathrm{c} 28}+0.271 h_{0} \\
&- 0.0083 t_{0}+1.74 \alpha-0.12 f_{\mathrm{cm}}\left(t_{0}\right), \\
& A=- 11.80+1.5 B+0.363 J_{\text {init }}+0.25 \sigma \\
&-0.144 f_{\mathrm{c} 28}+0.00122 \mathrm{RH}-1.25 h_{0} \\
&-0.0096 t_{0}+0.233 T \\
& B=19.795+0.356 A-0.0910 \sigma-0.00168 \mathrm{RH}+0.389 h_{0}+0.006955 t_{0} \\
&-0.0525 T
\end{aligned}
$$

where $f_{\mathrm{c} 28}$ is the compressive concrete strength at 28 days $(\mathrm{MPa}), f_{\mathrm{cm}}\left(t_{0}\right)$ the mean compressive concrete strength at $t_{0}(\mathrm{MPa}), h_{0}$ the notional cross-section size (mm), $T$ the temperature $\left({ }^{\circ} \mathrm{C}\right), \sigma$ the applied compressive stress (MPa), $\alpha$ an index related to the cement type (equal to $-1,0$ or 1 , for slow, normal and fast actions, respectively) and RH the relative humidity of the environment (\%).

Figure 3 compares the MPF predictions with the experimental results. The mean trend is much better fitted than for the case of the Eurocode 2 (Figure 2), as the bias of the results is removed. Nevertheless, the scatter is still to be considered as it depends on random phenomena in testing materials, conditions and procedures. The confidence interval at $95 \%$ shows that the range of uncertainty is very wide, especially for long-term creep. For this reason, we introduce herein a random variable $\delta$ in order to represent the model error associated to data scatter. As the

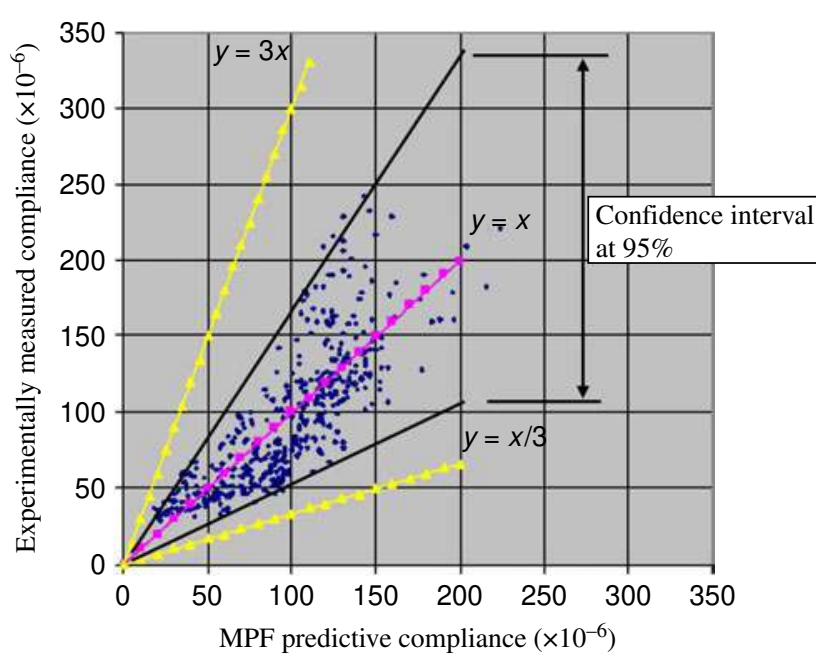

Figure 3. MPF prediction versus experimental compliance $\left(\mathrm{MPa}^{-1}\right)$.

confidence interval increases proportionally to the mean compliance, the probabilistic MPF model is rewritten in the form:

$$
J=\delta \times\left[J_{\text {init }}+A\left(1-\mathrm{e}^{-\left(\left(t-t_{0}\right) / 30\right)}\right)+B \log _{10}\left(\frac{t}{t_{0}}\right)\right],
$$

where $\delta$ represents the model error, with mean value equal to one, as the deterministic MPF corresponds to the best fitting of test results.

Figure 4 illustrates the histogram of the model error, as well as its best fitting using normal, lognormal and Weibull distributions, corresponding to the probability

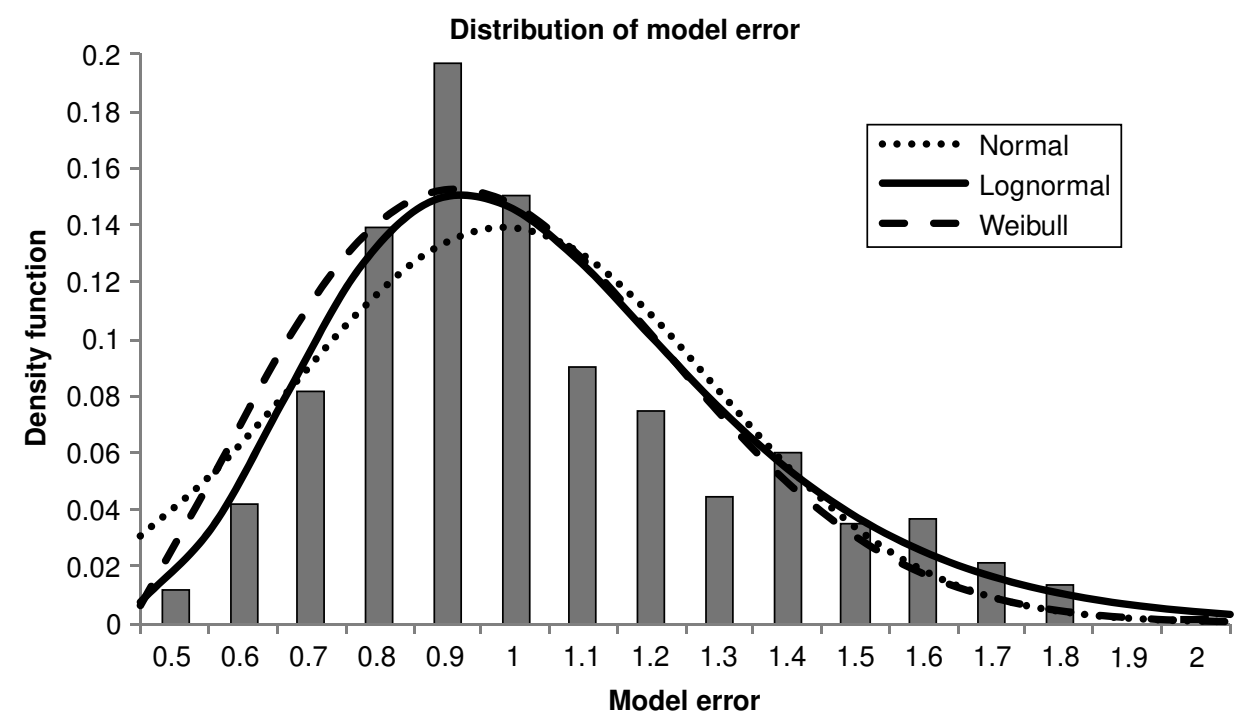

Figure 4. Probability density functions for the model error. 
density functions:

Normal density function :

$f_{\delta}(\delta)=\frac{1}{\sqrt{2 \pi} \times 0.287} \mathrm{e}^{-(1 / 2)((\delta-1) / 0.287)^{2}}$,

Lognormal density function :

$f_{\delta}(\delta)=\frac{1}{\sqrt{2 \pi} 0.287(\delta-0.06)} \mathrm{e}^{-(1 / 2)(\ln ((\delta-0.06)+0.041) / 0.287)^{2}}$,

Weibull density function :

$f_{\delta}(\delta)=\frac{2.2}{0.6}\left(\frac{\delta-0.48}{0.6}\right)^{1.2} \mathrm{e}^{-((\delta-0.48) / 0.6)^{2.2}}$.

These distributions correspond to respective mean and standard deviation equal to 1.00 and 0.287 for normal distribution, to 1.00 and 0.293 for lognormal distribution with a shift parameter of 0.06 , and to 1.46 and 0.255 for Weibull distribution with a shift parameter of 0.48 . The comparison of these three distributions (Figure 4) shows that the lognormal distribution fits better the model error tails, while normal and Weibull distributions overestimate the lower tail and underestimate the upper tail. The $\chi^{2}$ statistics is equal to 2802.3, 31.6 and 69.6 for normal, lognormal and Weibull distributions, respectively. In addition, the lognormal distribution is shown to model appropriately the extended effect in the upper tail, which is important for safe design. In other words, the lognormal distribution allows for larger amount of excessive creep strains, which is conformal to experimental observations. It is therefore suggested to use this distribution for creep error modelling in reliability analysis.

\section{Reliability analysis}

\subsection{Prestressed concrete deck}

Let us consider a simply supported bridge deck with a span of $24 \mathrm{~m}$ and road width of $7 \mathrm{~m}$. The cross section of the deck is shown in Figure 5. The deck is subjected to a permanent distributed load equal to $251 \mathrm{kN} / \mathrm{m}$ (including its own weight) and to a traffic load composed of a distributed load of $34 \mathrm{kN} / \mathrm{m}$ and a wheel load of $1.02 \mathrm{MN}$. The area of concrete cross section is $8.528 \mathrm{~m}^{2}$, its moment of inertia is $0.639 \mathrm{~m}^{4}$ and the centre of gravity is located at $0.56 \mathrm{~m}$ from the bottom of concrete cross section. The

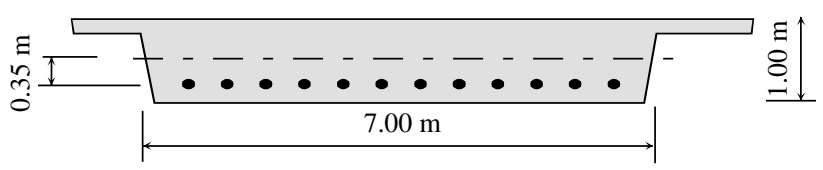

Figure 5. Prestressed concrete bridge deck.

characteristic concrete strength is $f_{\text {ck }}=40 \mathrm{MPa}$ and the prestressing cable eccentricity is $0.41 \mathrm{~m}$. The design according to Eurocode 2 (CEN, 2004) leads to 18 prestressing cables of type $12 \mathrm{~T} 17$ with cross section $A_{\mathrm{p}}=2850 \mathrm{~mm}^{2}$ and maximum force $P_{\max }=3.45 \mathrm{MN}$; the total prestressing force is therefore 62.1 MN. According to Eurocode 2, the losses due to creep are calculated as $\Delta P_{\mathrm{c}}=3.87 \mathrm{MN}$ and those due to other phenomena (including short term, shrinkage and relaxation) are 7.32 MN, leading to a net applied prestressing force of $50.92 \mathrm{MN}$.

The prestressing losses due to creep $\Delta P_{\mathrm{c}}$ can be computed by the Eurocode formula (CEN, 2004):

$$
\begin{aligned}
& \Delta P_{\mathrm{c}}= \\
& \frac{A_{\mathrm{p}}\left(E_{\mathrm{p}} / E_{\mathrm{cm}}\right) \varphi\left(t, t_{0}\right) \sigma_{\mathrm{c}, \mathrm{QP}}}{1+\left(E_{\mathrm{p}} / E_{\mathrm{cm}}\right)\left(A_{\mathrm{p}} / A_{\mathrm{c}}\right)\left(1+\left(A_{\mathrm{c}} / I_{\mathrm{c}}\right) z_{c p}^{2}\right)\left(1+0.8 \varphi\left(t, t_{0}\right)\right)},
\end{aligned}
$$

where $A_{\mathrm{c}}, I_{\mathrm{c}}$ and $E_{\mathrm{cm}}$ are, respectively, the concrete area, the moment of inertia and the mean elasticity modulus, $A_{\mathrm{p}}$ and $E_{\mathrm{p}}$ are the prestressing steel area and elasticity modulus, respectively, $z_{\mathrm{cp}}$ is the position of the prestressing cables, $\varphi\left(t, t_{0}\right)$ is the creep coefficient and $\sigma_{\mathrm{c}, \mathrm{QP}}$ is the stress on concrete around the cables under quasi-permanent loading.

\subsection{Creep models}

In this section, the EC2 model is compared with the MPF model, with respect to structural uncertainties. The random variables are given in Table 1 where the distribution types and standard deviations are obtained as follows:

- The concrete compressive strength $f_{\mathrm{c}}$ is lognormally distributed with a coefficient of variation of 0.15 , as suggested in the JCSS model code (JCSS, 2000) as

Table 1. Random variable distributions and parameters.

\begin{tabular}{lllccc}
\hline Variable & \multicolumn{1}{c}{ Symbol } & \multicolumn{1}{c}{ Distribution } & Mean & Standard deviation & Coefficient of variation $(\%)$ \\
\hline Concrete strength & $f_{\mathrm{c}}(\mathrm{MPa})$ & Lognormal & 48 & 4.86 & 10.13 \\
Dead load & $g(\mathrm{kN} / \mathrm{m})$ & Lognormal & 251 & 25.1 & 10.00 \\
Prestressing force & $P_{0}(\mathrm{MN})$ & Lognormal & $62.1 / 69.0$ & $1.24 / 1.38$ & 2.00 \\
Cable eccentricity & $\mathrm{e}_{0}(\mathrm{~m})$ & Normal & 0.41 & 0.01 & 2.44 \\
Model error & $\delta$ & Lognormal (shift $=0.06)$ & 1.00 & 0.293 & 29.3 \\
Relative humidity & $\mathrm{RH}(\%)$ & Lognormal, truncated at 100\% & 80 & 5 & 6.25 \\
\hline
\end{tabular}


Table 2. Statistical parameters and failure probabilities for various predictive creep models.

\begin{tabular}{lccccccc}
\hline & \multicolumn{3}{c}{ Without model error } & & \multicolumn{2}{c}{ With model error } \\
\cline { 2 - 3 } Case model & Mean & Standard deviation & $20 \%$ loss probability & & Mean & Standard deviation & $20 \%$ loss probability \\
\hline Eurocode 2 & 3.872 & 0.602 & $9.3 \times 10^{-18}$ & & 3.876 & 1.220 & $2.9 \times 10^{-8}$ \\
MPF (18 cables) & 7.960 & 1.182 & $5.8 \times 10^{-5}$ & & 7.652 & 2.550 & $3.8 \times 10^{-2}$ \\
MPF (20 cables) & 10.48 & 1.307 & $8.4 \times 10^{-3}$ & & 10.26 & 3.288 & $1.5 \times 10^{-1}$ \\
\hline
\end{tabular}

well as in many papers (e.g. Aoues \& Chateauneuf, 2008; Biondini \& Frangopol, 2009).

- The coefficient of variation of the prestressing force $P_{0}$ is deduced from engineering practice (Freyssinet, 2012) and recommendations (BPEL91, 1999).

- The deviation of cable eccentricity $e_{0}$ is based on recommendations (CEN, 1992; Freyssinet, 2012).

- Regarding the model error $\delta$, the distribution type and standard deviation are derived from the statistical analysis performed in the present paper.

- The standard deviation of the relative humidity RH is obtained by considering typical weather records; as lognormal distribution is adopted for the relative humidity, the distribution has to be truncated at $100 \%$ to keep the variation in the physical range.

- Finally, the dispersion of dead load $g$ and live loads $U D L$ and $T S$ are defined according to usual assumptions in the literature (e.g., JCSS, 2000).

Under quasi-permanent loading conditions, the maxim stress on the bridge deck is $14.6 \mathrm{MPa}$, which is below $0.4 f_{c k}=16 \mathrm{MPa}$. In this study, three models are compared:

- EC2 - Design and creep models according to Eurocodes: this case corresponds to standard design conditions, but does not meet the real conditions due to EC2 deviations regarding test results.

- MPF18 - Design based on Eurocodes (18 cables) while creep is calculated by MPF: this case allows us to calculate the effective losses when the deck is designed according to the Eurocodes; as the real losses are higher than those of EC2, this case cannot satisfy the serviceability limit state.

- MPF20 - Design using MPF (20 cables) and creep calculated by the same model: this case considers full design using the MPF creep model, which is more coherent with field observations; it can be noticed that two additional cables are required to satisfy real creep losses (i.e. the required initial prestress is $69 \mathrm{MN}$ instead of $62.1 \mathrm{MN}$ ).

Table 2 provides the mean values and standard deviations of the calculated prestress losses due to creep, with and without considering the model error. It is important to remind that the model error considered in this study represents the deviation between the theoretical model predictions and the experimental test results; its probability distribution, mean value and standard deviation are characterised in Section 2.3. In this sense, the model error includes mechanical and statistical uncertainties affecting the theoretical predictive model. Figure 6 depicts the various distributions of the creep-induced losses of prestressing. The effect of the model errors on the scatter of losses can be clearly observed, especially for MPF20. Although the prestressing losses mean is $3.87 \mathrm{MN}$ for EC2, it grows to $7.96 \mathrm{MN}$ for MPF with the same number of cables (i.e. 18 cables), and to $10.48 \mathrm{MN}$ when 20 cables are used. The comparison of the two first cases shows that the EC2 underestimates the mean and standard deviation of the losses by almost $50 \%$. For this reason, the design performed by the EC2 cannot fulfil the serviceability limit state which has been effectively observed on several structures (Rapahel, 2002).

The standard deviations of losses predictions are at least doubled when the model errors are considered: while the coefficient of variation is about $15 \%$ without considering the model errors, it increases to $32 \%$ under the effect of this error. This large dispersion explains why field observations are often far from design prescriptions. This fact highlights the need for accurate predictive creep models. The probability of losing $20 \%$ of the prestressing force by creep is given in Table 2 for various cases. This condition may be considered as catastrophic for structural serviceability and even durability when cracks take place. Although this event is seen as practically impossible for EC2 without considering model error $\left(9.3 \times 10^{-18}\right)$, the

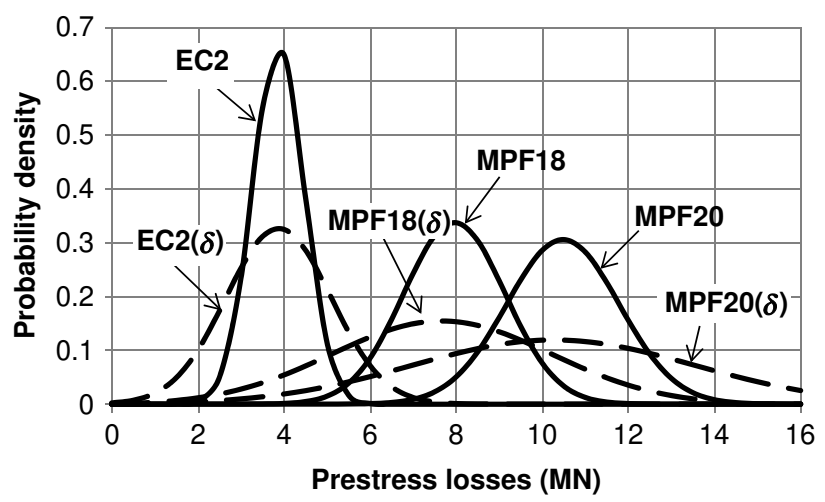

Figure 6. Distributions of prestress creep losses with and without model error $(\delta)$. 

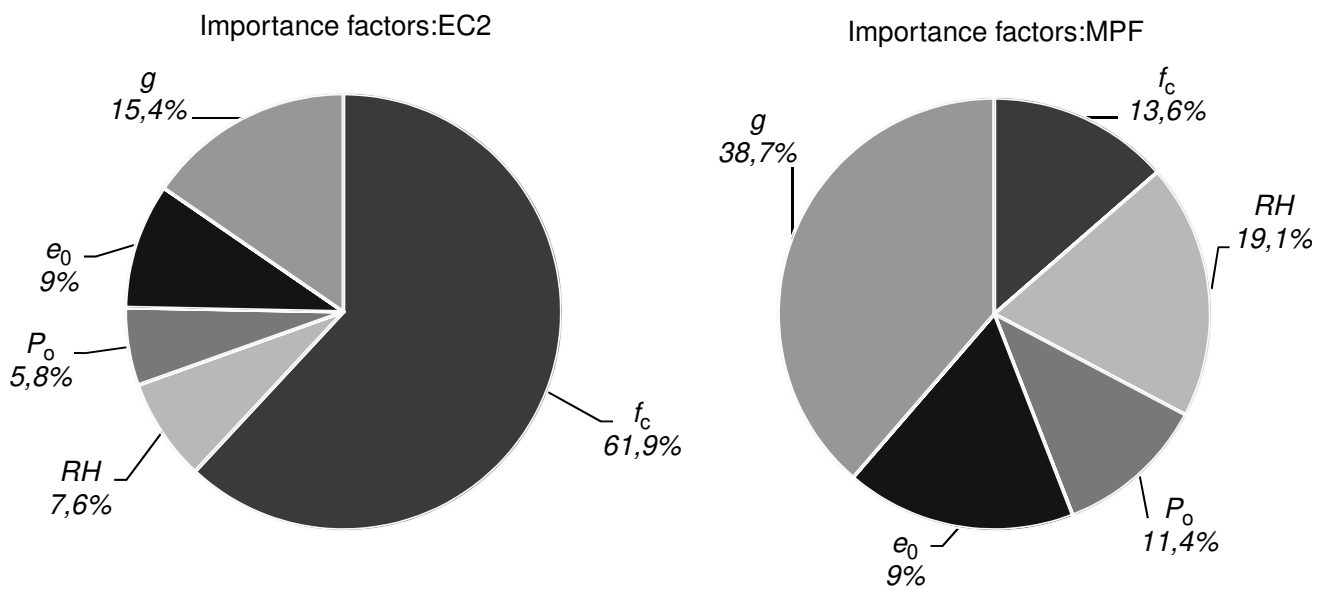

Figure 7. Importance factors for EC2 and MPF.

failure probability becomes very significant for MPF18 considering model error $\left(3.8 \times 10^{-2}\right)$. The higher failure probabilities for MPF20, compared with MPF18, can be explained by the larger percentage of mean creep losses in addition to larger standard deviations, due to the increase in the concrete compressive stress. The increase in the number of cables has strong effects on the failure probability (reaching up to $15 \%$ for the considered structure), and safe solutions could not be found without increasing the concrete cross section.

Figure 7 depicts the importance of the input variables on the scatter of the creep losses. It can be observed that the most important variables are the mean compressive strength (61.9\%) and the dead load (15.4\%) for the EC2, while they are mainly the dead load (38.7\%) and the relative humidity (19.1\%) for the MPF model. As the prestressing force and position are well controlled during construction, their effects on reliability are very small and their uncertainties can be neglected for this limit state. The importance of the compressive strength is strongly reduced in the MPF. In general, the importance factors are better distributed on most of the variables for the MPF than those for the EC2 where $61.9 \%$ are related to the compressive strength. This distribution of the importance is interesting from the design point of view, because an error in one parameter has lower impact on the member reliability assessment, leading to robust design. Moreover, as the dead load can be more accurately evaluated than the local concrete strength, the MPF leads to less scattered creep predictions in practical use.

\subsection{Reliability analysis}

In this part of the study, the design rule is considered to be violated when the tensile stress in concrete $\sigma_{\max }$ exceeds the tensile strength $f_{\mathrm{ct}}$, leading to cracking under traffic loading. In this case, the failure probability is given by $P_{\mathrm{f}}=\operatorname{Pr}\left[\sigma_{\max }>f_{\mathrm{ct}}\right]$, which can be evaluated by the firstorder reliability method (FORM) (Ditlevsen \& Madsen, 1996; Enevoldsen, 2011; Neves, Chateauneuf, \& Venturini, 2008). It is important to remind that, in this study, 'failure' does not mean 'collapse', but simply the violation of the design criterion. The random variables in this analysis are given in Table 3 .

Figure 8 plots the evolution of the serviceability failure probability as a function of the structure age. It can be seen that this probability grows quickly in the first years, especially for the EC2 model where creep is localised in the first 5 years. At 50 years of service, the failure probability is $1.8 \times 10^{-2}$ for EC2, $9.4 \times 10^{-2}$ for MPF18

Table 3. Random variable distributions and parameters.

\begin{tabular}{|c|c|c|c|c|c|}
\hline Variable & Symbol & Distribution & Mean & Standard deviation & Coefficient of variation (\%) \\
\hline Compressive strength & $f_{\mathrm{c}}(\mathrm{MPa})$ & Lognormal & 48 & 4.86 & 10.13 \\
\hline Tensile strength & $f_{\mathrm{ct}}(\mathrm{MPa})$ & Lognormal & 3.5 & 0.7 & 20.00 \\
\hline Dead load & $g(\mathrm{kN} / \mathrm{m})$ & Lognormal & 251 & 25.1 & 10.00 \\
\hline Uniform live load & $\mathrm{UDL}(\mathrm{kN} / \mathrm{m})$ & Lognormal & 34 & 5.1 & 15.00 \\
\hline Concentrated live load & $\mathrm{TS}(\mathrm{MN})$ & Lognormal & 1.02 & 15.3 & 15.00 \\
\hline Prestressing force & $P_{0}(\mathrm{MN})$ & Lognormal & $62.1 / 69.0$ & $1.24 / 1.38$ & 2.00 \\
\hline Cable eccentricity & $\mathrm{e}_{0}(\mathrm{~m})$ & Normal & 0.41 & 0.01 & 2.44 \\
\hline Model error & $\delta$ & Lognormal $($ shift $=0.48)$ & 1.00 & 0.293 & 29.30 \\
\hline Relative humidity & RH $(\%)$ & Lognormal, truncated at $100 \%$ & 80 & 5 & 6.25 \\
\hline
\end{tabular}




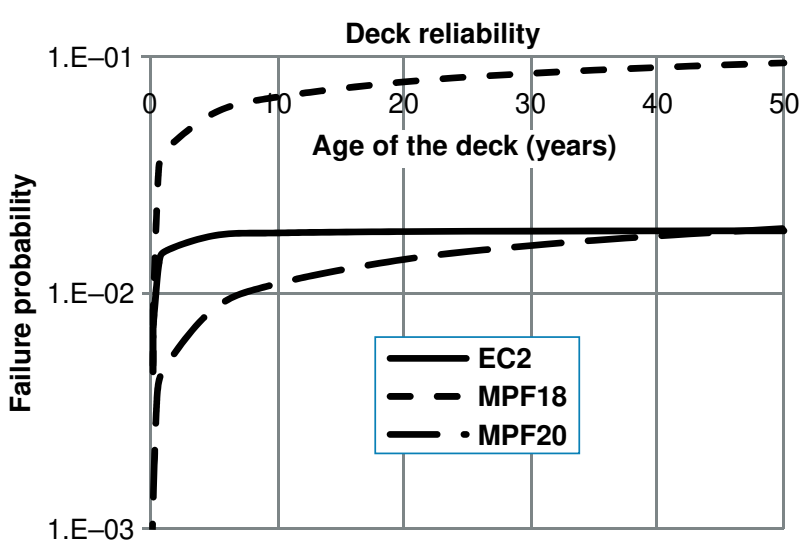

Figure 8. Serviceability failure probability as a function of deck age.

and $1.85 \times 10^{-2}$ for MPF20. While the two design cases EC2 and MPF20 give similar failure probabilities regarding the serviceability limit state, the MPF18 shows a failure probability five times more than in the two other cases. We can conclude that the EC2 overestimates the deck reliability by a factor of 5 , which is not appropriate for design purpose. The use of 20 cables instead of 18 leads to reliability levels which are higher than those assumed by the EC2 in the range from 0 to 50 years.

For instance, the statistical error in creep models has not yet been considered. As shown in Section 2.3, the feedback from real tests shows a wide variation regarding the predictive models and consequently the model error should be included in the reliability analysis. Figure 9 compares the importance of the variables when the model error is considered (the relative humidity is omitted for clarity). The live and dead loads show the largest effects on the deck reliability regarding concrete cracking: they have $63 \%$ of importance for MPF20 and up to $82.3 \%$ for EC2. On the other hand, the concrete compressive strength, and the prestressing force and eccentricity have small effects on the creep loss predictions, i.e. $<7 \%$ for the three variables.
It is important to note that although the compressive strength has significant effect on creep losses (Figure 7), its importance decreases for cracking limit state because creep loss is just a small portion of the total prestressed force, in addition to the dominant effect of the applied loads (i.e. an influence reduction takes place for uncertainties related to internal variables). We can also observe that, while the effect of concrete tensile strength is almost constant (about 8.5\%), the model error has larger importance in the MPF model than in the EC2.

Figure 10 plots the deck reliability when the model error is included as a random variable (Table 3). At 50 years of service, the failure probability increases to $1.9 \times 10^{-2}$ for EC2, $1.2 \times 10^{-1}$ for MPF18 and $3.4 \times 10^{-2}$ for MPF20. The consideration of the model error has small influence on the EC2, while it increases the failure probability by a factor of 2 in the case of MPF20. From another point of view, the modelling of the EC2 dispersion is not sufficient to provide realistic estimation of reliability (i.e. $1.9 \times 10^{-2}$ instead of $1.2 \times 10^{-1}$ ). This wrong estimation is explained by the bias of the EC2 fitting with respect to real data points, which cannot be recovered by simply considering a large dispersion in the model.

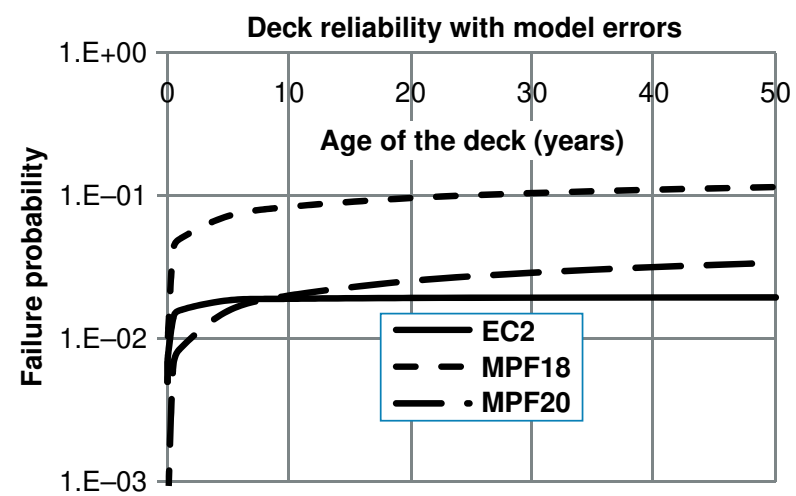

Figure 10. Serviceability failure probability as a function of deck age, with model errors.
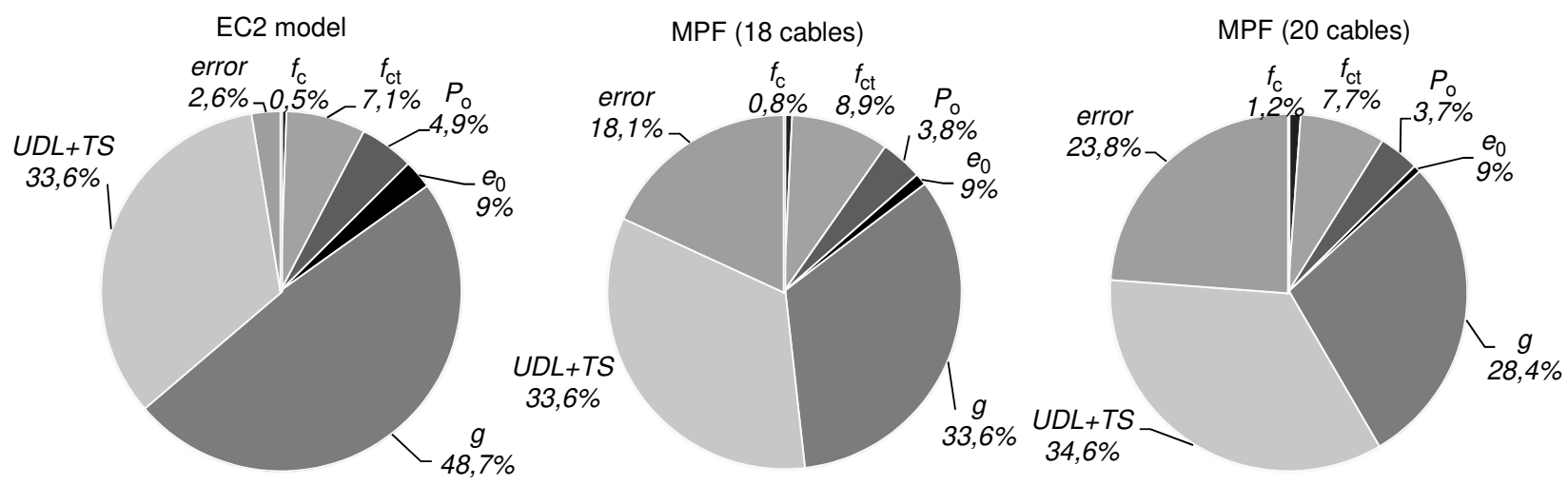

Figure 9. Importance factors for cracking limit state (50 years). 


\section{Conclusions}

The viscoelastic behaviour of prestressed concrete structures has significant effects on long-term losses, leading to serious risks regarding the serviceability limit state. The creep model defined by the Eurocode 2 is compared with a probabilistic phenomenological model developed on the basis of a large database. The reliability analysis shows the impact of the model parameters on the dispersion of the predictive creep losses. This study shows that the model error plays a significant role in prestressed structure design.

Two aspects of prediction error should be considered, namely the deviation of the average trend and the dispersion around this average. The first type results from the insufficiency of modelling creep physics and its relationship with structural and environmental conditions. In this sense, the proposed model gives satisfaction. The second type of error should take into consideration the epistemic uncertainties in testing conditions, as well as the randomness in real structural conditions. This effect could not be neglected as we have shown in this work that the creep prediction scatter plays a significant role in establishing the design rules for prestressed structures, which is mandatory to fit the target reliability. It is therefore recommended to put further research effort to characterise the predictive creep prediction errors for large-scale infrastructures.

\section{References}

Aoues, Y., \& Chateauneuf, A. (2008). Reliability-based optimization of structural systems by adaptive target safety - Application to RC frames. Structural Safety, 30, 144-161.

Bažant, Z.P., \& Carol, I. (1974). Rate type creep law of ageing concrete based on Maxwell chain. Materials and Structures, 7, 45-60.

Bažant, Z.P., \& Guang-Hua, L. (2008). Unbiased statistical comparison of creep and shrinkage prediction models. ACI Materials Journal, 105, 610-621.

Bažant, Z.P., Yu, Q., \& Li, G.-H. (2012). Excessive long-time deflections of prestressed box girders. I: Record-span bridge in Palau and other paradigms. ASCE Journal of Structural Engineering, 138, 676-696.

Biondini, F., \& Frangopol, D.M. (2009). Lifetime reliabilitybased optimization of reinforced concrete cross-sections under corrosion. Structural Safety, 31, 483-489.

BPEL 91 (1999). French code for prestressed concrete: « Règles techniques de conception et de calcul des ouvrages et constructions en béton précontraint suivant la méthode des états-limites » - Fascicule ${ }^{\circ} 62$ Titre I Section II du CCTG - BPEL 91 revised April 1999.

CEN (2004). Eurocode 2: Design of concrete structures - Part 11: General rules and rules for buildings, EN 1992-1-1. Part 2: Concrete bridges, EN 1992-1-2.

Chazal, C., \& Moutou Pitti, R. (2010). Viscoelastic incremental formulation using creep and relaxation differential approaches. Mechanics of Time-Dependent Materials, 14, 173-190.
Delhomme, F., Baroudi, D., \& Debicki, G. (2009). Behaviour of anchor rods under pullout and relaxation tests. (ed. Tanabe, et al.,). Creep, shrinkage and durability mechanics of concrete and concrete structures. London: Taylor \& Francis Group, ISBN 978-0-415-48508-1.

Destrebecq, J.F., \& Jurhiewiez, B. (2001). A numerical method for the analysis of rheologic effects in concrete bridges. Computer Aided Civil Infrastructures Engineering, 16, 347-364.

Ditlevsen, O., \& Madsen, H. (1996). Structural reliability methods. New York: John Wiley \& Sons.

Enevoldsen, I. (2011). Practical implementation of probability based assessment methods for bridges. Structure and Infrastructure Engineering, 7, 535-549.

Freyssinet (2012). Freyssibar Prestressing system. Freyssinet Group. http://www.freyssibar.com

Gabrielsen, B.L. (1968). Stochastic models for viscoelastic materials. Materials and Structures, 1, 319-326.

Ghazlan, G., Caperaa, S., \& Petit, C. (1995). An incremental formulation for the linear analysis of thin viscoelastic structures using generalised variables. International Journal of Numerical Methods Engineering, 38, 33153333.

Goel, R., Kumar, R., \& Paul, D. (2007). Comparative study of various creep and shrinkage prediction models for concrete. Journal of Materials in Civil Engineering, 19, 249-260.

JCSS (2000). Part 3: Material Properties. http://www.jcss.byg. dtu.dk Probabilistic Model Code. Joint Committee on Structural Safety.

Jordan, I.J. (1980). Models for creep of concrete, with special emphasis on probabilistic aspects. Materials and Structures, $13,29-40$.

Judycki, J. (1992). Non-linear viscoelastic behaviour of conventional and modified asphaltic concrete under creep. Materials and Structures, 25, 95-101.

Lemaire, M., Chateauneuf, A., \& Mitteau, J.C. (2010). Structural reliability. West Sussex, UK: ISTE Ltd and John Wiley \& Sons, ISBN 978-1-84821-082-0.

Miyagawa, T. (2006). Maintenance of concrete structures in Japan: Current activities. Structure and Infrastructure Engineering, 2, 131-139.

Mohsen, A.I., \& Ahmad, A. (1995). Prestress losses in fiberglass pretensioned concrete compression member. Materials and Structures, 28, 330-339.

Moutou Pitti, R., Dubois, F., Pop, O., \& Absi, J. (2009). A finite element analysis for mixed mode crack growth in a viscoelastic and orthotropic medium. International Journal of Solids and Structures, 46, 3548-3555.

Moutou Pitti, R., Dubois, F., \& Petit, C. (2010). Generalization of $\mathrm{T}$ and $\mathrm{A}$ integrals to time-dependent materials: Analytical formulations. International Journal of Fracture, 161, 187-198.

Neves, R., Chateauneuf, A., \& Venturini, S. (2008). Component and system reliability analysis of nonlinear reinforced concrete grids with multiple failure modes. Structural Safety, 30, $183-199$.

Raphael, W. (2002). Etude fiabiliste du fluage des structures en béton armé et précontraint. PhD Thesis, Ecole Centrale Paris, France.

Raphael, W., Faddoul, R., El-Asmar Selouan, D., \& Chateuneuf, A. (2009). Information-based formulation for Bayesian updating of the Eurocode 2 Creep Model. Structural Concrete Journal, 10(2), 1-55. 
Raphael, W., Kaddah, F., Geara, F., Favre, J.-L., \& Calgaro, J.-A. (2002). Nouveau modèle de calcul pour la prédiction du fluage du béton. Annals of Buildings and Public Works, ITBTP, no. 5, France.

Seongcheol, C., Soo Won Cha, S., \& Hwan, B. (2010). On identification of viscoelastic behavior for early-age concrete based on measured strain and stress histories. Materials and Structures, 43, 1161-1175.
Soares, R., Chateauneuf, A., Venturini, W.-S., \& Lemaire, M. (2002). Reliability analysis of nonlinear reinforced concrete frames using the response surface method. Reliability Engineering and System Safety, 75(1), 1-16.

Takács, P.F. (2002). Deformations in concrete cantilever bridges: Observations and theoretical modelling. $\mathrm{PhD}$ Thesis, Norwegian University of Science and Technology Trondheim, Norway. 